\title{
Risk of Recurrence and Transition to Chronic Disease in Acute Central Serous Chorioretinopathy
}

This article was published in the following Dove Press journal: Clinical Ophthalmology

\author{
Danial Mohabati $\mathbb{D}^{1,2}$ \\ Camiel JF Boon ${ }^{1,3}$ \\ Suzanne Yzer ${ }^{4}$ \\ 'Department of Ophthalmology, Leiden \\ University Medical Center, Leiden, the \\ Netherlands; ${ }^{2}$ Department of \\ Ophthalmology, Rotterdam Ophthalmic \\ Institute, Rotterdam, the Netherlands; \\ ${ }^{3}$ Department of Ophthalmology, \\ Academic Medical Center, University of \\ Amsterdam, Amsterdam, the \\ Netherlands; ${ }^{4}$ Department of \\ Ophthalmology, Rotterdam Eye Hospital, \\ Rotterdam, the Netherlands
}

Correspondence: Suzanne Yzer Rotterdam Eye Hospital, Department of Ophthalmology, Schiedamse Vest I80, Rotterdam 301 I BH, the Netherlands Tel +3I-I0-40I7777

Fax +31-10-4017699

Email S.Yzer@oogziekenhuis.nl
Purpose: To study the risk of recurrence in acute central serous chorioretinopathy (aCSC) and to evaluate the risk of transitioning to chronic CSC.

Patients and Methods: The medical records and multimodal imaging data of $295 \mathrm{aCSC}$ cases were reviewed. Typical aCSC was defined as the presence of serous subretinal fluid (SRF), one focal leakage spot on fluorescein angiography (FA), retinal pigment epithelium (RPE) alterations limited in area to less than one optic disc diameter, and complete recovery from this first CSC episode. An increase in RPE alterations combined with persistent SRF was considered a sign of chronicity, which was determined in cases with $>12$ months follow-up. The main outcome measures included final visual acuity, percentage of disease recurrence, and percentage of cases moving toward a chronic phenotype. Treatment strategies and their efficacy were also reviewed.

Results: A total of 295 eyes in 291 patients with aCSC were included. Spontaneous recovery was awaited in 154 eyes (52\%), whereas 141 eyes (48\%) recovered following treatment. SRF recurrence occurred in $24 \%$ of untreated cases and in $4 \%$ of treated cases $(\mathrm{p}<0.001)$. An analysis of 61 eyes that underwent an FA after $\geq 12$ months of follow-up revealed increased RPE alterations in 22 eyes (36\%), and 14 eyes (23\%) had both an increase in RPE alterations and SRF recurrence.

Conclusion: All aCSC cases recovered from the first disease episode, and none of the cases developed persistent SRF leakage. Among the cases for which long-term follow-up information was available, $36 \%$ showed a tendency toward chronicity in terms of increased RPE alterations, whereas $23 \%$ showed both an increase in RPE alterations and recurrent SRF. Early photodynamic therapy (PDT) may decrease the risk of recurrences.

Keywords: acute central serous chorioretinopathy, chronic CSC, photodynamic treatment, recurrent CSC

\section{Introduction}

Central serous chorioretinopathy (CSC) is characterized by an accumulation of serous fluid under the retina. ${ }^{1}$ This subretinal fluid (SRF) is believed to accumulate as the result of a dysfunctional, hyperpermeable choroid together with a disruption in the retinal pigment epithelium (RPE), which compromises the outer blood-retinal barrier. ${ }^{2}$

Generally, CSC can present as either an acute or chronic form. Acute CSC (aCSC) is usually self-limiting, with a good visual prognosis. ${ }^{2}$ In contrast, in chronic CSC, the SFR usually does not resolve spontaneously, and may result in irreversible photoreceptor damage, vision loss and a decreased vison-related quality of life. ${ }^{3-5}$ Therefore, treatment is generally recommended for chronic CSC.

It is unclear whether aCSC and cCSC are different entities or if they are part of a spectrum of diseases and whether aCSC can transition to $\mathrm{cCSC}$, and if so, what 
factors may contribute to this process. Also, there is no consensus regarding the exact period after which CSC should be considered chronic; some authors suggest that typical aCSC resolves spontaneously within 2-4 months, ${ }^{6}$ whereas others suggest a duration of 6 months. ${ }^{7,8}$ It is also unclear whether chronic CSC is usually preceded by aCSC.

There are clinical features in addition to disease duration that can help distinguish between acute CSC and chronic CSC. Chronic CSC tends to manifest with more widespread abnormalities on multimodal imaging compared to aCSC. ${ }^{9}$ In cCSC, optical coherence tomography (OCT) shows disruption of the outer retinal layers, RPE irregularities and/or detachment, and posterior cystoid retinal degeneration. ${ }^{10,11}$ Fluorescein angiography (FA) shows gravitational tracks, multiple "pin points" or diffuse RPE leakage, and/or widespread areas of atrophic RPE alterations. Indocyanine green angiography (ICGA) shows signs of multifocal hyperpermeable choroidal congestion and hyperpermeability. ${ }^{4}$ Fundus autofluorescence (FAF) imaging shows extensive hyper-autofluorescent and hypo-autofluorescent changes. ${ }^{12}$ Unlike chronic CSC, an episode of aCSC is generally defined as only a single leak on FA with minimal focal changes in the RPE. ${ }^{13-15}$

Little is known about which aCSC patients are at risk for developing recurrent and/or chronic CSC. Therefore, better insight into the clinical course, risk factors, and long-term outcome of aCSC can be helpful in determining whether these diseases largely overlap or are pathophysiologically and clinically distinct. Here, we reviewed a large number of patients who presented with their first episode of typical aCSC based on multimodal imaging characteristics. These patients were followed over time in order to evaluate the prevalence of recurrence and to identify the clinical features that can be used to predict the transition of aCSC to chronic CSC.

\section{Patients and Methods}

\section{Patient Selection}

This study was approved by the respective institutional review boards at the participating centers and was performed in accordance with the tenets of the Declaration of Helsinki. No written consent had to be collected for reviewing the medical records, as all data were anonymized upon collection. In this retrospective multicenter study, subjects were identified from a large cohort of CSC patients seen from January 2005 until December 2017 at two Dutch tertiary referral centers: The Department of Ophthalmology at Leiden University Medical Center (Leiden, the Netherlands) and the Rotterdam Eye Hospital (Rotterdam, the Netherlands). Patients who met the clinical definition of aCSC, had at least one follow-up visit, and had evidence of complete resolution of the first CSC episode were included. Acute CSC was defined as: 1. documented presence of SRF on OCT; 2 . only one focal leakage ("hot spot") on FA; 3. limited RPE alterations, including RPE detachment, less than one optic disc diameter. Patients were excluded when there was a suspicion of other possible causes of SRF accumulation, such as choroidal neovascularization, or polypoidal choroidal vasculopathy. In this study, previous steroid use was not an exclusion criterion.

\section{Clinical Examinations}

Patients underwent a range of ophthalmological and multimodal imaging examinations both at the time of diagnosis and during follow-up visits. These examinations included best-corrected visual acuity (BCVA, measured with a Snellen chart, then converted to ETDRS letters for statistical comparison); ${ }^{16}$ slit-lamp examination and/or color fundus photography (Topcon Corp., Tokyo, Japan or Carl Zeiss Meditec AG, Jena, Germany); spectral-domain OCT (Cirrus HD-OCT, Carl Zeiss Meditec, Jena, Germany, OCT-HS100, Canon Inc., Tokyo, Japan, or Spectralis HRA+OCT, Heidelberg Engineering, Heidelberg, Germany); fundus autofluorescence imaging (FAF) (Heidelberg Spectralis HRA+OCT or Topcon Corp.); FA (Topcon Corp., Spectralis HRA+OCT, or Carl Zeiss Meditec); and ICGA (Topcon Corp., Heidelberg Spectralis HRA+OCT, or Carl Zeiss Meditec).

\section{Clinical Outcome Measures}

For this study, patients were subdivided into the following two groups based on available follow-up data: patients with $\geq 12$ months follow-up, and patients with $<12$ months of follow-up. Only patients with $\geq 12$ months of follow-up data were included in our analysis of disease progression over time. Follow-up began at the first episode of CSC confirmed by an ophthalmologist and ended with the last available visit. The following clinical characteristics were obtained: presence and location of SRF on OCT; abnormalities on FAF; RPE alterations on FA; SRF leakage on FA; and the aspect of the hyperpermeable choroid areas on ICGA. In addition, the presence of RPE alterations in the unaffected contralateral eye was assessed. RPE alterations 
were defined as patches of granular hyperfluorescence as seen on mid-phase FA. The amount of RPE alterations, and the extension of the area of RPE alterations, were evaluated by two experienced retina specialists (SY and CJFB). All clinical management strategies were also reviewed and included photodynamic therapy (PDT), conventional thermal laser, subthreshold micropulse diode laser (SML), and a "wait-and-see" policy. CSC was considered to be recurrent when SRF returned at least once following complete resolution. Signs of chronic CSC were defined as the persistence and/or recurrence of SRF together with an increased area of cumulative RPE alterations based on follow-up FA imaging. Patients with aCSC who were followed for less than 12 months were contacted by telephone and questioned regarding any complaints suggestive of recurrent CSC (either with or without consulting an ophthalmologist) since their final follow-up visit.

\section{Statistical Analysis}

Statistical analyses were performed using IBM SPSS software for Windows, version 23 (IBM Corp., Armonk, NY, USA). Continuous numerical data were compared using either a paired or an unpaired samples Student's $t$-test. Categorical data were analyzed using a chi-square test. A univariate analysis was performed using Pearson's correlation in order to evaluate the correlation between relevant clinical findings. For all tests, a $p$-value of $<0.05$ was considered significant.

\section{Results}

\section{Demographic Characteristics}

The clinical records of 1378 patients with a diagnosis of CSC were reviewed. A total of 295 eyes in 291 patients met our strict definition of aCSC and were included in our analysis. For 201 eyes (68\%), $\geq 12$ months of follow-up data were available (mean: 37 months; range: 12-247 months); the mean follow-up time for the remaining 94 eyes was 5 months (range: 1-11 months). The demographic characteristics of these cases are summarized in Table 1. Four of the included patients had a history of bilateral aCSC with an average interval of 28 months (range: 6-63 months) between disease onset in the first affected eye and the second affected eye. Of the 73 female patients, five had a unilateral case of aCSC during pregnancy, and all five cases recovered spontaneously after delivery.
Table I Patient Demographics and Clinical Features

\begin{tabular}{|l|l|}
\hline Feature & Value \\
\hline Patients (eyes) & 29 I (295) \\
Age at diagnosis in years, mean \pm SD & $44 \pm 9$ \\
Male gender, N (\%) & $220(75 \%)$ \\
Caucasian, N (\%) & $244(83 \%)$ \\
Recent steroid use, N (\%) & $59(20 \%)$ \\
Pregnancy-associated CSC, N (\%) & $5(1.7 \%)$ \\
BCVA at diagnosis, in ETDRS letters, mean \pm SD & $79 \pm 9(\sim 20 / 25)$ \\
(Snellen equivalent) & \\
Mean follow-up duration (range) & 27 months (I-247) \\
\hline
\end{tabular}

Abbreviations: BCVA, best corrected visual acuity; CSC, central serous chorioretinopathy; ETDRS, Early Treatment Diabetic Retinopathy Study.

\section{Optical Coherence Tomography}

OCT imaging was available for all 295 eyes at diagnosis and for 292 eyes (99\%) at the final follow-up visit. SRF on OCT at disease onset was subfoveal in 286 eyes (97\%) and extrafoveal in 7 eyes (2\%); in the remaining 2 eyes (1\%), SRF resolved in the period between the fundus examination and the first imaging examination. Unresolved SRF was present at the final available OCT examination in 7 out of 292 eyes (2\%) (Table 2).

\section{Fundus Autofluorescence Imaging}

FAF imaging was available for 199 eyes $(67 \%)$ at the time of diagnosis and for 77 eyes (26\%) at the final follow-up visit. At diagnosis, CSC-associated FAF changes at the site of serous neuroretinal detachment could be categorized as: focal hyperautofluorescent lesion (21 eyes, 10\%), hypo-autofluorescent lesions (54 eyes, 27\%), a combination of both lesions (33 eyes, $17 \%$ ), and speckled (ie, granular) hyper-autofluorescent lesion with mottled hyper-autofluorescent dots (63 eyes, 32\%) (Table 2, and Figure 1).

\section{Fluorescein Angiography}

FA imaging was available at the time of diagnosis for 232 eyes (79\%). Long-term follow-up FA data were available for 61 eyes $(21 \%)$ with a mean interval of $37 \pm 33$ months between the initial diagnosis and the final follow-up visit. At diagnosis, no RPE alterations were present in 91 eyes (39\%), whereas minimal RPE alterations were observed in the remaining 141 eyes $(61 \%)$. These RPE changes were located in the fovea in 24 of these 141 eyes $(10 \%), 1$ disc diameter (DD) round but excluding the fovea in 41 eyes (18\%), and 1 DD away from the fovea in 60 eyes $(26 \%)$. Minimal RPE alterations and RPE detachment were present in more than one area in 16 eyes (7\%) (Table 2 ). 
Table 2 Clinical Findings on Multimodal Imaging at Diagnosis and During Follow-Up

\begin{tabular}{|c|c|c|c|c|c|c|}
\hline & & & \multirow{2}{*}{$\begin{array}{l}\text { Imaging at } \\
\text { Baseline } \\
\text { Entire } \\
\text { Cohort } \\
\text { (n=295 Eyes) }\end{array}$} & \multicolumn{3}{|l|}{ Last Available Imaging } \\
\hline & & & & $\begin{array}{l}\text { Cases with }<12 \text { Months } \\
\text { Follow-Up ( } n=94 \text { Eyes) }\end{array}$ & $\begin{array}{l}\text { Cases with } \geq 12 \text { Months } \\
\text { Follow-Up ( } n=201 \text { Eyes) }\end{array}$ & $\begin{array}{l}\text { Entire } \\
\text { Cohort } \\
(n=295 \text { Eyes) }\end{array}$ \\
\hline \multirow[t]{2}{*}{ OCT } & Eyes with available OCT & & 295 eyes & 94 eyes & 198 eyes & 292 eyes \\
\hline & Location SRF (\%) & $\begin{array}{l}\text { No SRF } \\
\text { Central } \\
\text { Peripheral }\end{array}$ & $\begin{array}{l}2(1) \\
286(97) \\
7(2)\end{array}$ & $\begin{array}{l}89(95) \\
3(3) \\
2(2)\end{array}$ & $\begin{array}{l}196(99) \\
2(1) \\
0\end{array}$ & $\begin{array}{l}285(97) \\
5(2) \\
2(1)\end{array}$ \\
\hline \multirow[t]{2}{*}{ FAF } & Eyes with available FAF & & 199 eyes & 10 eyes & 67 eyes & 77 eyes \\
\hline & Abnormalities (\%) & $\begin{array}{l}\text { No abnormalities } \\
\text { Hyper- } \\
\text { autofluorescent } \\
\text { lesions } \\
\text { Hypo- } \\
\text { autofluorescent } \\
\text { lesions } \\
\text { Both lesions } \\
\text { Speckled hyper- } \\
\text { autofluorescent } \\
\text { lesion }\end{array}$ & $\begin{array}{l}28(14) \\
21(10) \\
54(27) \\
33(17) \\
63(32)\end{array}$ & $\begin{array}{l}3(30) \\
5(50) \\
I(10) \\
I(10) \\
0\end{array}$ & $\begin{array}{l}11(16) \\
12(18) \\
25(37) \\
19(29) \\
0\end{array}$ & $\begin{array}{l}14(18) \\
17(22) \\
26(34) \\
20(26) \\
0\end{array}$ \\
\hline \multirow[t]{6}{*}{ FA } & Eyes with available FA & & 232 eyes & 3 eyes & 61 eyes & 64 eyes \\
\hline & Location RPE alterations (\%) & $\begin{array}{l}\text { No RPE } \\
\text { alterations } \\
\text { Foveal } \\
<\text { I DD from fovea } \\
>\text { I DD from fovea } \\
\text { Multiple locations }\end{array}$ & $\begin{array}{l}91(39) \\
24(10) \\
41(18) \\
60(26) \\
16(7)\end{array}$ & $\begin{array}{l}0 \\
\text { I (33) } \\
\text { I (33) } \\
\text { I (33) } \\
0\end{array}$ & $\begin{array}{l}10(16) \\
6(10) \\
13(21) \\
27(44) \\
5(9)\end{array}$ & $\begin{array}{l}10(15) \\
7(11) \\
14(22) \\
28(44) \\
5(8)\end{array}$ \\
\hline & Composition RPE alterations (\%) & $\begin{array}{l}\text { Monofocal } \\
\text { Multifocal }\end{array}$ & $\begin{array}{l}75(53) \\
66(47)\end{array}$ & $\begin{array}{l}2(66) \\
\text { I (33) }\end{array}$ & $\begin{array}{l}28(55) \\
23(45)\end{array}$ & $\begin{array}{l}30(56) \\
24(44)\end{array}$ \\
\hline & $\begin{array}{l}\text { RPE alterations in contralateral } \\
\text { eye (\%) }\end{array}$ & $\begin{array}{l}\text { No RPE } \\
\text { alterations } \\
\text { Minimal RPE } \\
\text { alterations } \\
\text { Bilateral CSC } \\
\text { Missing image }\end{array}$ & $\begin{array}{l}135(58) \\
90(39) \\
6(2) \\
1(1)\end{array}$ & $\begin{array}{l}0 \\
0 \\
3(100) \\
0\end{array}$ & $\begin{array}{l}33(54) \\
23(38) \\
5(8) \\
0\end{array}$ & $\begin{array}{l}33(52) \\
23(36) \\
8(12) \\
0\end{array}$ \\
\hline & $\begin{array}{l}\text { Location of "hot spot" of leakage } \\
\text { on FA (\%) }\end{array}$ & $\begin{array}{l}\text { Foveal } \\
<\text { I DD from fovea } \\
>\text { I DD from fovea }\end{array}$ & $\begin{array}{l}39(17) \\
89(38) \\
104(45)\end{array}$ & $\begin{array}{l}\text { I (33) } \\
\text { I (33) } \\
\text { I (33) }\end{array}$ & $\begin{array}{l}4(7) \\
14(24) \\
9(15)\end{array}$ & $\begin{array}{l}5(8) \\
15(24) \\
10(16)\end{array}$ \\
\hline & Hot spot morphology (\%) & $\begin{array}{l}\text { Smoke stack } \\
\text { Ink blot }\end{array}$ & $\begin{array}{l}47(20) \\
185(80)\end{array}$ & $\begin{array}{l}0 \\
3(100)\end{array}$ & $\begin{array}{l}2(4) \\
25(42)\end{array}$ & $\begin{array}{l}2(3) \\
28(45)\end{array}$ \\
\hline \multirow[t]{3}{*}{ ICGA } & Eyes with available ICGA & & 54 eyes & 4 eyes & 19 eyes & 23 eyes \\
\hline & $\begin{array}{l}\text { Composition hyperpermeable area } \\
\text { (\%) }\end{array}$ & $\begin{array}{l}\text { Monofocal } \\
\text { Multifocal }\end{array}$ & $\begin{array}{l}34(63) \\
20(37)\end{array}$ & $\begin{array}{l}\text { I (25) } \\
3(75)\end{array}$ & $\begin{array}{l}11(58) \\
8(42)\end{array}$ & $\begin{array}{l}\text { I2 (52) } \\
\text { II (48) }\end{array}$ \\
\hline & $\begin{array}{l}\text { Hyperpermeable area compared } \\
\text { to RPE alterations area on FA (\%) }\end{array}$ & $\begin{array}{l}\text { Equal to FA } \\
\text { Smaller than FA } \\
\text { Larger than FA }\end{array}$ & $\begin{array}{l}24(44) \\
0 \\
30(56)\end{array}$ & $\begin{array}{l}0 \\
0 \\
4(100)\end{array}$ & $\begin{array}{l}11(58) \\
0 \\
8(42)\end{array}$ & $\begin{array}{l}11(48) \\
0 \\
12(52)\end{array}$ \\
\hline
\end{tabular}

Abbreviations: CSC, central serous chorioretinopathy; DD, optical disc diameter; FA, fluorescein angiography; FAF, fundus autofluorescence; ICGA, indocyanine green angiography; OCT, optical coherence tomography; RPE, retinal pigment epithelium; SRF, subretinal fluid. 


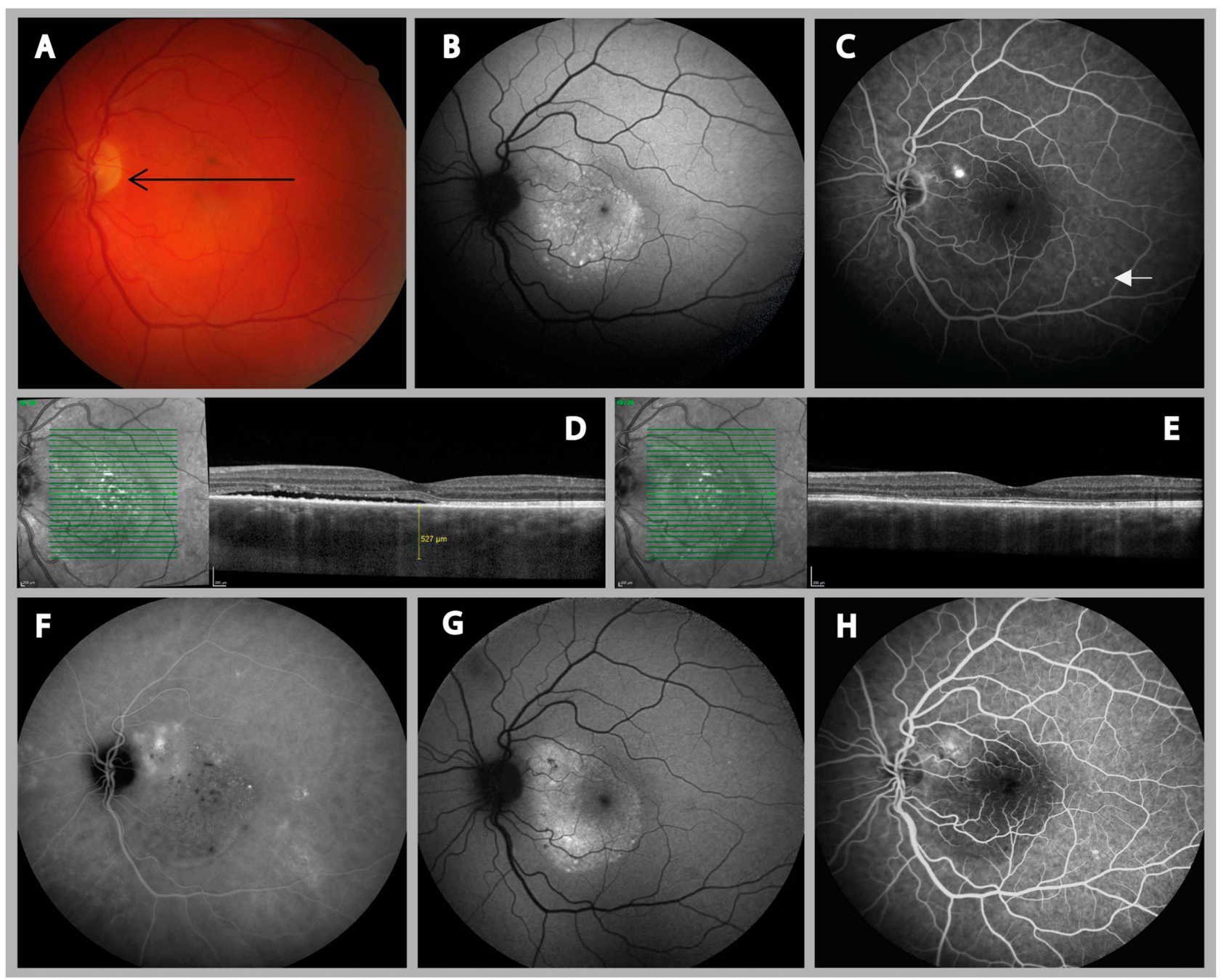

Figure I Clinical features visible on multimodal imaging of the left eye of a 37 -year-old male patient with aCSC. (A) Color fundus photograph showing small pigment clustering in the macula and a silhouette of the serous retinal detachment. The arrow indicates the scanning plane, which is depicted on the SD-OCT. (B) FAF image at diagnosis showing a speckled (ie, granular) hyper-autofluorescent lesion at the site of the serous neuroretinal detachment. (C) FA imaging revealed a single "hot spot" of leakage and a typical small detachment of the RPE above the inferior retinal arcade (arrow). (D) An SD-OCT scan at diagnosis revealed SRF accumulation, a thickened choroid, and subretinal debris, presumably consisting of non-phagocytized photoreceptor outer segments. (E) SRF resolved spontaneously within a few weeks. (F) The areas of hyper-fluorescence on mid-phase ICGA revealed diffuse choroidal hyperpermeability that was larger than the leakage site visible on FA. A recurrent episode I.5 years later was treated with two subthreshold micropulse diode laser but did not result in resolution of the SRF. Eventually, half-dose photodynamic therapy resulted in resolution of the SRF ( $\mathbf{G}$ and $\mathbf{H}$ ). At the patient's final visit II months later, hyper-autofluorescent and hypo-autofluorescent abnormalities were visible (G), and FA imaging revealed a slightly enlarged area of RPE alterations $(\mathbf{H})$

Abbreviations: aCSC, acute central serous chorioretinopathy; ICGA, indocyanine green angiography; FA, Fluorescein angiography; FAF, Fundus autofluorescence; SD-OCT, spectral-domain optical coherence tomography; SRF, subretinal serous fluid; RPE, retinal pigment epithelium.

\section{Indocyanine Green Angiography}

ICGA imaging was available for 54 eyes $(18 \%)$ at diagnosis and 23 eyes $(8 \%)$ at the final visit, which was on average $11 \pm 15$ months after the first ICGA. On mid-phase ICGA (ie, 10 minutes), a monofocal hyperfluorescent and hyperpermeable region in the choroid was visible in 34 eyes $(63 \%)$. Multifocal hyperfluorescent lesions were seen in 20 eyes (37\%), even though all of the patients included in this study had only one leakage spot on FA imaging (Table 2, Figure 2). At the time of diagnosis, 30 eyes (56\%) had a hyperfluorescent ICGA lesion that exceeded the size of the RPE alteration shown on FA imaging; in the remaining 24 eyes (44\%), the extent of the hyperfluorescent choroidal abnormalities was equal to the extent of the RPE alterations on FA (Table 2, Figure 2).

\section{Treatment, Resolution of SRF, and Visual Outcome}

In total, 154 eyes (52\%) had spontaneous resolution of the first aCSC episode (the wait-and-see group) $14.8 \pm 11.6$ weeks after diagnosis; the remaining 141 eyes (48\%) received treatment (applied on average 13.7 \pm 12.7 weeks 

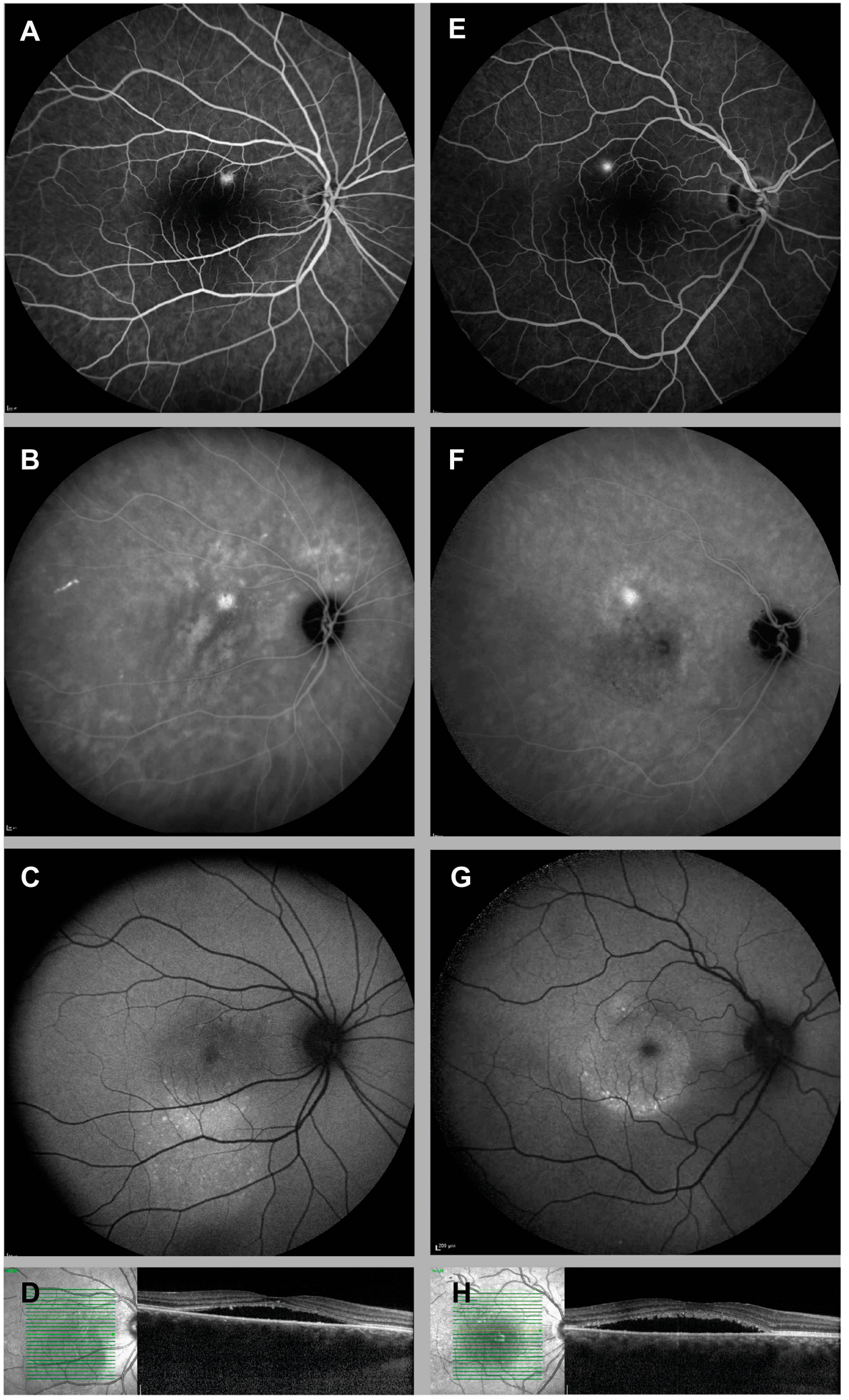

Figure 2 Clinical features visible on multimodal imaging of the right eye of a 37-year-old female patient (A-D) and a 34-year-old male patient (E-H) with aCSC. (A and E) FA revealed one focal "hot spot" of leakage and no changes in the retinal pigment epithelium. (B and F) Despite these circumscribed lesions on FA, ICGA revealed a more widespread area of hyper-fluorescence, which corresponded with multifocal (B) or monofocal (F) choroidal leakage. (C and G) FAF imaging revealed speckled (ie, granular) hyperautofluorescent changes at the site of serous neuroretinal detachment in both patients, which corresponded with serous retinal detachment visualized on OCT (D, H).

Abbreviations: aCSC, acute central serous chorioretinopathy; ICGA, indocyanine green angiography; FA, Fluorescein angiography; FAF, Fundus autofluorescence; OCT, optical coherence tomography; SRF, subretinal serous fluid; RPE, retinal pigment epithelium. 
after diagnosis) and all resolved, on average in 9.6 \pm 10.2 weeks after this treatment. SRF resolution occurred significantly faster after treatment compared to resolution after a wait-and-see strategy $(p<0.001)$. The choice of treatment modalities, which was at the discretion of the treating physician, is summarized in Table 3.

The average subjective reported interval between the onset of complaints and aCSC diagnosis was 4 weeks (range: 0-52 weeks; median: 1 week) in the early-treated patients, and 6 weeks (range: 0-52 weeks; median: 1 week) in the wait-and-see group; this difference was not significant $(p=0.136)$. Moreover, these two groups did not differ significantly with respect to the location of the leakage "hot spot" ( $p=0.540)$, the presence of RPE alterations ( $p=0.821)$, or the extent of the RPE alterations $(p=0.439)$.

Mean BCVA in the entire patient cohort was $79 \pm 9$ ETDRS letters (Snellen equivalent: 20/25) at the time of diagnosis and increased significantly to $86 \pm 6$ ETDRS

Table 3 Treatment Modalities and Specifications During FollowUp in Patients with Acute CSC

\begin{tabular}{|c|c|c|c|c|}
\hline & & \multicolumn{3}{|c|}{ Study Eyes } \\
\hline & & $\begin{array}{l}\text { Entire } \\
\text { Cohort }\end{array}$ & $\begin{array}{l}\text { Cases with } \\
<12 \text { Months } \\
\text { Follow-Up }\end{array}$ & $\begin{array}{l}\text { Cases with } \\
\geq 12 \text { Months } \\
\text { Follow-Up }\end{array}$ \\
\hline \multicolumn{2}{|c|}{$\begin{array}{l}\text { Eyes not treated at first episode } \\
\text { [wait-and-see approach] (\%) }\end{array}$} & $154(52)$ & $47(50)$ & $107(51)$ \\
\hline \multicolumn{2}{|c|}{$\begin{array}{l}\text { Eyes treated at first episode } \\
\text { [early-treatment group] (\%) }\end{array}$} & |4| (48) & $47(50)$ & 94 (49) \\
\hline \multirow{3}{*}{$\begin{array}{l}\text { Treatment } \\
\text { specifications at } \\
\text { first episode (\%) }\end{array}$} & $\mathrm{PDT}^{\mathrm{a}}$ & $134(95)$ & $43(92)$ & 91 (97) \\
\hline & $\begin{array}{l}\text { Conventional } \\
\text { laser }\end{array}$ & $3(2)$ & $2(4)$ & I (I) \\
\hline & SML & $4(3)$ & $2(4)$ & $2(2)$ \\
\hline \multicolumn{2}{|c|}{$\begin{array}{l}\text { Eyes with additional treatments } \\
\text { after first episode (\%) }\end{array}$} & $23(8)$ & I (I) & $22(11)$ \\
\hline \multicolumn{2}{|c|}{$\begin{array}{l}\text { Average number of retreatments } \\
\text { (range) }\end{array}$} & I (I-2) & $2(2-2)$ & I (I-2) \\
\hline \multirow{3}{*}{$\begin{array}{l}\text { Re-treatment } \\
\text { specifications } \\
\text { (\%) }\end{array}$} & $\mathrm{PDT}^{\mathrm{b}}$ & 71 (93) & I (50) & $70(94)$ \\
\hline & $\begin{array}{l}\text { Conventional } \\
\text { laser }\end{array}$ & $2(3)$ & 0 & $2(3)$ \\
\hline & SML & $3(4)$ & I (50) & $2(3)$ \\
\hline
\end{tabular}

Notes: ${ }^{a} 56$ (42\%) eyes received half-dose PDT, 67 (50\%) eyes received half-time PDT, and II eyes (8\%) had unknown PDT settings; mean spot size: I746 I I $09 \mu \mathrm{m}$. b28 (39\%) eyes received half-dose PDT, 40 (57\%) eyes received half-time PDT, and 3 (4\%) eyes had full PDT settings; mean spot size: $2066 \pm 1256 \mu \mathrm{m}$.

Abbreviations: CSC, central serous chorioretinopathy; PDT, photodynamic therapy; SML, subthreshold micropulse diode laser.
(Snellen equivalent: $20 / 20$ ) letters at the final follow-up visit $(p<0.001)$. Initial BCVA in the early-treated group was significantly lower than in the wait-and-see group (78 \pm 9 ETDRS letters (Snellen equivalent: 20/32) versus $80 \pm 9$ ETDRS letters (Snellen equivalent: $20 / 25$ ), respectively; $p=0.017$ ), but did not differ significantly between groups at the final follow-up visit $(86 \pm 5$ ETDRS letters (Snellen equivalent: $\sim 20 / 20$ ) versus $86 \pm 7$ ETDRS letters respectively; $p=0.971$ ). In total, final BCVA was $\geq 80$ ETDRS letters (Snellen equivalent: $\sim 20 / 25$ ) in $94 \%$ of eyes, and $\geq 85$ ETDRS letters (Snellen equivalent: 20/20) in $76 \%$.

\section{Self-Reported Complaints}

Among patients with $<12$ months clinical follow-up (94 aCSC eyes), 3 patients (3 eyes, 3\%) reported additional aCSC episodes through telephone survey. None of these patients had consulted an ophthalmologist since all reported episodes had resolved spontaneously. One patient reported 5 aCSC episodes during 2 years, each lasting less than 1 week. The second patient reported 2 episodes in 2 years, lasting for less than 2 weeks each. The third case reported 2 episodes during 3 years each lasting for less than 1 week (Figure 3).

\section{Transition to Recurrent and/or Chronic CSC}

Among the 201 eyes with $\geq 12$ months of documented follow-up data, 75 (37\%) had an average of 1.4 recurrences (range: 1-6 recurrences) with a mean follow-up of 53 months (range: 13-247 months). Among the 94 eyes with $<12$ months of follow-up data, 9 eyes (10\%) had an average of 1.3 recurrences (range: 1-2 recurrences) documented by an ophthalmologist; 3 additional eyes had documented selfreported recurrences through the telephone survey. Thus, from the original cohort of 295 eyes with aCSC, a total of 87 eyes (29\%) had evidence of recurrent CSC. The prevalence of SRF recurrence was significantly higher in the wait-andsee group compared to the early-treated group ( $24 \%$ versus $4 \%$, respectively; $p<0.001$ ). Moreover, Pearson's correlation analysis revealed a significant correlation between treatment and reduced risk of recurrence $(\mathrm{R}=-0.333$; $p<0.001)$. No other significant correlation was found between any demographic or clinical characteristics and the risk of recurrence, with the sole exception of the patient's age at diagnosis $(\mathrm{R}=-0.161 ; p=0.005)$, which was on average 4 years lower in the patients with a recurrence compared to the patients without a recurrence 


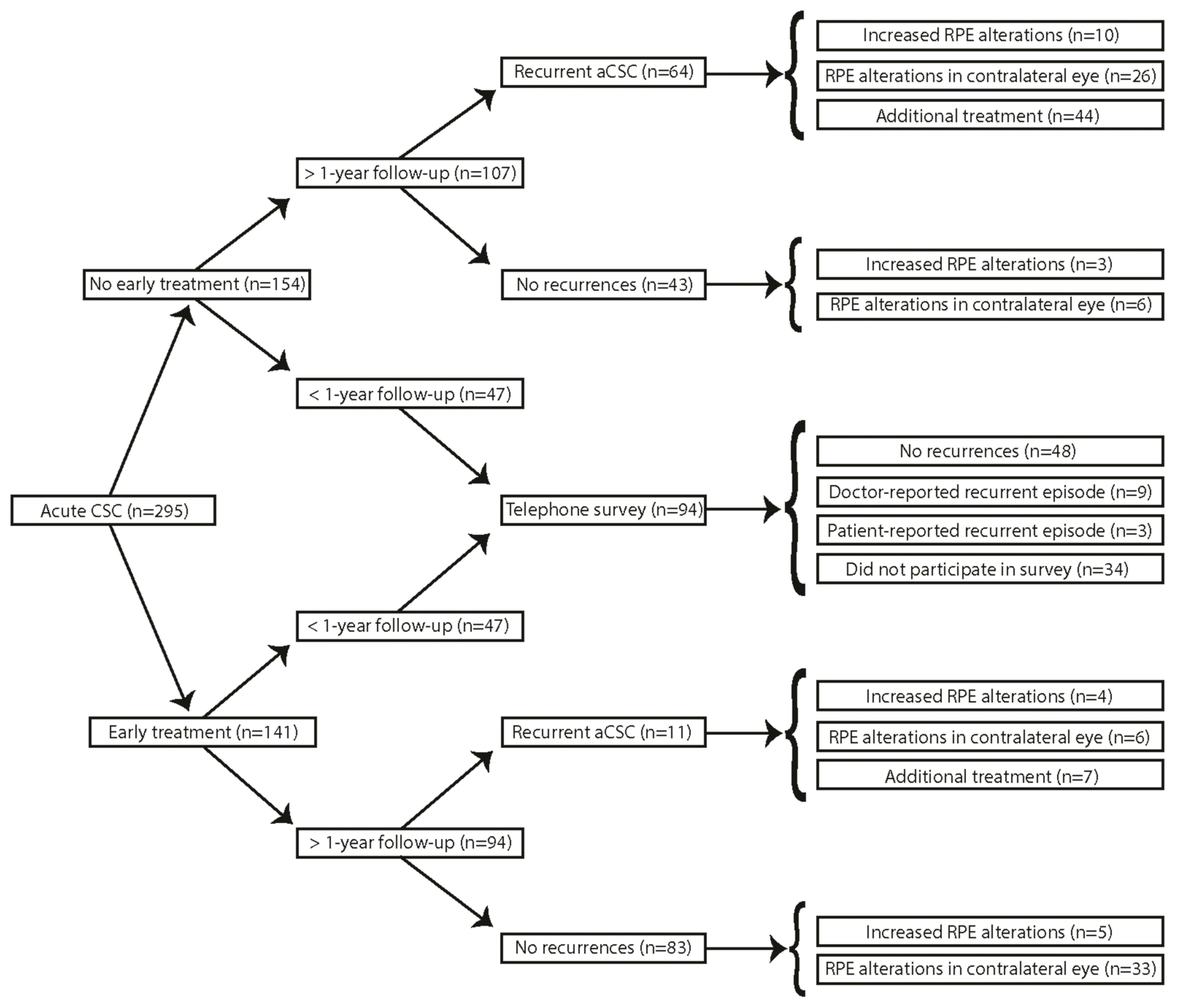

Figure 3 Flow chart depicting the distribution of the eyes in this study, with follow-up durations indicated. The development of CSC over time is based on recurrence of the disease, progression of RPE alterations, and the need for additional treatments.

Abbreviations: CSC, cute central serous chorioretinopathy; RPE, retinal pigment epithelium.

(41 years versus 45 years, respectively; $p=0.005$ ). The distribution of eyes with recurrent disease and additional treatment are summarized in Figure 3.

With respect to the progression of RPE alterations in the 61 eyes (21\%) with long-term follow-up FA examination, a clear increase in lesion size was observed in 22 of these eyes (36\%). In 14 of these eyes (23\%) both an increase in RPE alterations and recurrent SRF was observed. Furthermore, 23 unaffected contralateral eyes (37\%) had minimal RPE alterations - but no active disease - at the final followup visit. A significant correlation was found between the progression of RPE alterations in the affected eyes and the presence of RPE alterations in the unaffected contralateral eyes at the final follow-up visit $(\mathrm{R}=0.346$; $p=0.008)$. Among the 201 eyes with $\geq 12$ months of follow-up data, 10 eyes $(10 / 107,9 \%)$ in the wait-andsee group and 4 eyes $(4 / 94,4 \%)$ in the early-treated group had both SRF recurrence and an increased area of RPE alterations (Figure 3). However, a Pearson's correlation analysis showed no correlation between the progression of RPE alterations on one side, and the wait-and-see or treatment strategy on the other side $(\mathrm{R}=-0.103 ; p=0.448)$. Finally, disease recurrence (presence of SRF) was not significantly correlated with the progression of RPE alterations $(\mathrm{R}=0.258 ; p=0.162)$. 


\section{Discussion}

Little is currently known regarding the risk of acute CSC transitioning to a chronic form of CSC. Previous reports indicated that $8-16 \%$ of patients with chronic CSC have a history of aCSC. ${ }^{6,17}$ In our retrospective study, $36 \%$ of eyes with long-term follow-up data began as typical aCSC and showed a clear progression of RPE alterations over time; therefore, these patients showed a tendency toward chronic disease. Wong et al previously reported a higher percentage of progressive RPE alterations (61\%) in a smaller cohort of 25 patients with aCSC who were followed for at least 5 years after initial resolution; however, they found no correlation between this progression and visual acuity. ${ }^{18}$

In addition to changes in the RPE, persistent SRF is a characteristic feature of chronic CSC. ${ }^{19}$ In our study, none of the patients with long-term follow-up data had chronic persistent SRF. However, $23 \%$ of these patients had a combination of recurrent SRF and progressive RPE alterations, which could be considered chronic CSC in the strictest sense, as the presence of increased RPE changes alone may not necessarily be considered evidence of chronic disease. Nevertheless, an increase in RPE changes in the absence of active SRF leakage may still be a sign of chronic dysfunction of the underlying choroid. CSC is considered part of the pachychoroid disease spectrum, which is characterized by a congested and hyperpermeable choroid. ${ }^{20}$ In CSC, a thickened, leaking choroid may exert pressure on the overlying RPE, gradually causing structural changes that can lead to the focal breakdown of the outer blood-retina barrier formed by the RPE, with subsequent serous neuroretinal detachment. ${ }^{21}$ Bilateral RPE changes are often present in patients with pachychoroid pigment epitheliopathy. ${ }^{21-23}$ In our cohort, $61 \%$ of affected eyes and $42 \%$ of unaffected contralateral eyes had minimal (ie, $<1$ DD) RPE changes at the time of diagnosis, consistent with pachychoroid pigment epitheliopathy. In this condition, chronic changes in the choroid are common and are often independent of active leakage. Therefore, an objective increase in RPE alterations may actually be a more robust indicator of chronic disease than the duration of persisting SRF, as is currently customary in clinical practice. $^{24}$

In our study, $29 \%$ of all cases had a recurrence of SRF. This percentage includes patients with limited documented follow-up data and patients who self-reported an episode by telephone survey. However, when considering only the patients with objective long-term follow-up data, the prevalence of recurrent SRF leakage was higher (37\%). Therefore, our data suggest that the true rate of recurrence in typical aCSC lies somewhere between $29 \%$ and $37 \%$, which is consistent with the sole study published regarding this topic. ${ }^{25}$ In our analysis, although the patients with recurrent disease were significantly younger than the nonrecurrent patients, no other demographic or clinical characteristics were associated with the recurrence of SRF Disease recurrence was also not correlated with progressive changes in the RPE, which are often considered an important sign of a more chronic form of CSC. This might suggest that underlying choroidal changes - without active SRF leakage - are sufficient to cause changes in the RPE. Therefore, to a certain extent chronic CSC and recurrent CSC might represent two distinct disease entities. However, even in these cases we cannot exclude the possibility of intermittent mild SRF leakage as the cause of progressive RPE changes.

There is currently no universally accepted classification of clinical CSC subtypes, and the description and terminology of CSC and its subtypes is therefore a topic of debate. For example, some groups have proposed the following five categories for classifying the various phenotypes: acute CSC, non-resolving CSC, recurrent CSC, chronic CSC, and inactive CSC ${ }^{14,26}$ Matet et al recently reported a strong correlation between increased choroidal thickness and the risk of recurrence in CSC. ${ }^{25} \mathrm{~A}$ similar mechanism of action might have been present in our cohort. Although our data set lacked sufficient numbers of choroidal thickness measurements to assess this putative correlation, we frequently observed a thickened choroid (Figure 1). In our study cohort, SRF resolved faster in the treatment group compared to the wait-and-see group, and the prevalence of SRF recurrence was significantly lower in the group that received treatment ( $4 \%$ versus $24 \%$ respectively), the majority of whom received PDT with reduced settings. Similarly, Ozkaya et al reported a twofold higher rate of recurrence in 41 untreated self-limiting aCSC cases compared to 36 aCSC patients who were treated with low-fluence PDT $(51 \%$ vs $25 \%$, respectively). ${ }^{27}$ Given that PDT treatment exerts its effects at the level of the choroid, it is conceivable that PDT not only accelerates the resorption of SRF by alteration of choroidal circulation, ${ }^{28}$ but it may also play a role in remodeling the choriocapillaris and Haller's layer vessels, thereby reducing choroidal thickness and the risk of disease recurrence. ${ }^{29}$ 
This study has some limitations that warrant discussion. First, due to the cross-sectional design, the patient data and imaging examinations were not available at similar follow-up intervals. We therefore only studied a subgroup of patients with relatively long-term followup FA data. Second, given that follow-up FA examinations are usually performed in cases of recurrent SRF and/or the suspicion of other retinal abnormalities, this subgroup may have been subject to selection bias. A third possible limitation is that the patients who had early complete recovery were often referred back to the referring ophthalmologist, and were therefore lost to follow-up. We attempted to address this issue by conducting telephone surveys of these patients; however, $36 \%$ of these patients could not be reached. Finally, some patients in the early-treatment group were treated relatively soon after diagnosis. This treatment may have been due to relatively worse visual acuity and/or a longer history of subjective complaints; however, subjective complaints duration did not differ significantly between the wait-and-see group and the early-treated group. Therefore, we cannot exclude the possibility that at least some of the patients in the earlytreatment group would have resolved spontaneously without treatment.

\section{Conclusion}

We report that approximately one-third of aCSC cases developed a recurrent episode of SRF leakage. An increase of atrophic RPE alterations was seen in 36\% of the cases with long-term follow-up, and an increase of RPE alterations together with recurrent SRF in $23 \%$ of the cases; however, none of the patients in our study developed long-term chronic, persistent SRF leakage. Moreover, the presence of RPE alterations in the unaffected contralateral eye was associated with an increase in RPE alterations in the affected eye, possibly reflecting chronic disease. Treatment with lowsetting PDT may be an effective means to significantly reduce the risk of recurrence, but prospective randomized controlled studies are needed to address this topic. Finally, our data suggest that there may be a certain degree of clinical overlap between aCSC and chronic CSC, as a subgroup of aCSC cases had both recurrent SRF and increased RPE alterations that may be viewed as signs of a transition to a more chronic form of the disease. In the future, long-term prospective studies will likely provide important insights into possible new biomarkers for predicting the transition to chronic CSC, and genetic studies may shed light on possible genetic risk factors.

\section{Ethics and Consent Statement}

All procedures performed in this study, which involved human participants, were in accordance with the ethical standards of the institutional and/or national research committee, and with the 1964 Helsinki declaration and its later amendments or comparable ethical standards. The local institutional review boards in all participating centers ("Medisch Ethische Toetsingscommissie" (METC) in Leiden University Medical Center, and the "Wetenschapscommissie" in the Rotterdam Eye Hospital) did not require written consent from the participants for reviewing their medical records, as all data were anonymized upon collection.

\section{Acknowledgments}

This research was supported by the following funding sources: Stichting Leids Oogheelkundig Ondersteuningsfonds, Rotterdamse Stichting Blindenbelangen, Stichting Wetenschappelijk Onderzoek Het Oogziekenhuis, Macula Fonds, Landelijke Stichting voor Blinden en Slechtzienden, Retina Netherlands, and BlindenPenning. CJFB was supported by a Gisela Thier Fellowship from Leiden University and a ZonMw Veni grant from the Netherlands Organization for Scientific Research (NWO). These sponsors and funding organizations played no role in the design or conduct of this research.

\section{Disclosure}

The authors report no conflicts of interest in this work. An abstract version of these results was presented at the 2018 annual meeting of the Association for Research in Vision and Ophthalmology.

\section{References}

1. Piccolino FC, de la Longrais RR, Ravera G, et al. The foveal photoreceptor layer and visual acuity loss in central serous chorioretinopathy. Am J Ophthalmol. 2005;139(1):87-99. doi:10.1016/j.ajo.2004.08.037

2. Gemenetzi M, De Salvo G, Lotery AJ. Central serous chorioretinopathy: an update on pathogenesis and treatment. Eye. 2010;24 (12):1743-1756. doi:10.1038/eye.2010.130

3. Spaide RF, Campeas L, Haas A, et al. Central serous chorioretinopathy in younger and older adults. Ophthalmology. 1996;103(12):2070-2079. doi:10.1016/S0161-6420(96)30386-2

4. Breukink MB, Dingemans AJ, den Hollander AI, et al. Chronic central serous chorioretinopathy: long-term follow-up and vision-related quality of life. Clin Ophthalmol. 2017;11:39-46. doi:10.2147/OPTH.S115685

5. Wang MS, Sander B, Larsen M. Retinal atrophy in idiopathic central serous chorioretinopathy. Am J Ophthalmol. 2002;133(6):787-793. doi:10.1016/S0002-9394(02)01438-1

6. Liew G, Quin G, Gillies M, Fraser-Bell S. Central serous chorioretinopathy: a review of epidemiology and pathophysiology. Clin Exp Ophthalmol. 2013;41(2):201-214. doi:10.1111/j.1442-9071.2012.028 48.x 
7. Yannuzzi LA, Slakter JS, Kaufman SR, Gupta K. Laser treatment of diffuse retinal pigment epitheliopathy. Eur J Ophthalmol. 1992;2 (3):103-114. doi:10.1177/112067219200200301

8. Eandi CM, Ober M, Iranmanesh R, et al. Acute central serous chorioretinopathy and fundus autofluorescence. Retina. 2005;25 (8):989-993. doi:10.1097/00006982-200512000-00006

9. von Winning CH, Oosterhuis JA, Renger-van Dijk AH, et al. Diffuse retinal pigment epitheliopathy. Ophthalmologica. 1982;185(1):7-14. doi:10.1159/000309216

10. Yang L, Jonas JB, Wei W. Optical coherence tomography-assisted enhanced depth imaging of central serous chorioretinopathy. Invest Ophthalmol Vis Sci. 2013;54(7):4659-4665. doi:10.1167/iovs.1210991

11. Piccolino FC, De La Longrais RR, Manea M, Cicinelli S. Posterior cystoid retinal degeneration in central serous chorioretinopathy. Retina. 2008;28(7):1008-1012. doi:10.1097/IAE.0b013e31816b4b86

12. Eandi CM, Piccolino FC, Alovisi C, et al. Correlation between fundus autofluorescence and central visual function in chronic central serous chorioretinopathy. Am J Ophthalmol. 2015;159(4):652-658. doi:10.1016/j.ajo.2014.12.023

13. Zhao M, Zhang F, Chen Y, et al. A $50 \%$ vs $30 \%$ dose of verteporfin (photodynamic therapy) for acute central serous chorioretinopathy: one-year results of a randomized clinical trial. JAMA Ophthalmol. 2015;133(3):333-340. doi:10.1001/jamaophthalmol.2014.5312

14. Wang M, Munch IC, Hasler PW, et al. Central serous chorioretinopathy. Acta Ophthalmol. 2008;86(2):126-145. doi:10.1111/j.1600-0420.2007. 00889.x

15. Nicholson B, Noble J, Forooghian F, Meyerle C. Central serous chorioretinopathy: update on pathophysiology and treatment. Surv Ophthalmol. 2013;58(2):103-126. doi:10.1016/j.survophthal.2012. 07.004

16. Gregori NZ, Feuer W, Rosenfeld PJ. Novel method for analyzing snellen visual acuity measurements. Retina. 2010;30(7):1046-1050. doi:10.1097/IAE.0b013e3181d87e04

17. Yannuzzi LA, Shakin JL, Fisher YL, Altomonte MA. Peripheral retinal detachments and retinal pigment epithelial atrophic tracts secondary to central serous pigment epitheliopathy. 1984. Retina. 2012;32(Suppl 1):1554-1572. doi:10.1097/IAE.0b013e3182434da4

18. Wong R, Chopdar A, Brown M. Five to 15 year follow-up of resolved idiopathic central serous chorioretinopathy. Eye. 2004;18(3):262-268. doi:10.1038/sj.eye.6700637
19. Loo RH, Scott IU, Flynn HW Jr., et al. Factors associated with reduced visual acuity during long-term follow-up of patients with idiopathic central serous chorioretinopathy. Retina. 2002;22(1):19-24. doi:10.10 97/00006982-200202000-00004

20. Gallego-Pinazo R, Dolz-Marco R, Gomez-Ulla F, et al. Pachychoroid diseases of the macula. Med Hypothesis Discov Innov Ophthalmol. 2014;3(4):111-115.

21. Warrow DJ, Hoang QV, Freund KB. Pachychoroid pigment epitheliopathy. Retina. 2013;33(8):1659-1672. doi:10.1097/IAE.0b01 3e3182953df4

22. Agrawal R, Chhablani J, Tan KA, et al. Choroidal vasculopathy index in central serous chorioretinopathy. Retina. 2016;36(9):1646-1651. doi:10.1097/IAE.0000000000001040

23. Kim HC, Cho WB, Chung H. Morphologic changes in acute central serous chorioretinopathy using spectral domain optical coherence tomography. Korean J Ophthalmol. 2012;26(5):347-354. doi:10.33 41/kjo.2012.26.5.347

24. Dansingani KK, Balaratnasingam C, Mrejen S, et al. Annular lesions and catenary forms in chronic central serous chorioretinopathy. Am J Ophthalmol. 2016;166:60-67. doi:10.1016/j.ajo.2016.03.025

25. Matet A, Daruich A, Zola M, Behar-Cohen F. Risk factors for recurrences of central serous chorioretinopathy. Retina. 2017;38:1403-1414. doi:10.1097/IAE.0000000000001729

26. Daruich A, Matet A, Dirani A, et al. Central serous chorioretinopathy: recent findings and new physiopathology hypothesis. Prog Retin Eye Res. 2015;48:82-118. doi:10.1016/j.preteyeres.2015.05.003

27. Ozkaya A, Alkin Z, Ozveren M, et al. The time of resolution and the rate of recurrence in acute central serous chorioretinopathy following spontaneous resolution and low-fluence photodynamic therapy: a case-control study. Eye. 2016;30(7):1005-1010. doi:10.1038/ eye. 2016.79

28. Ober MD, Yannuzzi LA, Do DV, et al. Photodynamic therapy for focal retinal pigment epithelial leaks secondary to central serous chorioretinopathy. Ophthalmology. 2005;112(12):2088-2094. doi:10. 1016/j.ophtha.2005.06.026

29. Kang NH, Kim YT. Change in subfoveal choroidal thickness in central serous chorioretinopathy following spontaneous resolution and low-fluence photodynamic therapy. Eye. 2013;27(3):387-391. doi:10.1038/eye.2012.273
Clinical Ophthalmology

\section{Publish your work in this journal}

Clinical Ophthalmology is an international, peer-reviewed journal covering all subspecialties within ophthalmology. Key topics include: Optometry; Visual science; Pharmacology and drug therapy in eye diseases; Basic Sciences; Primary and Secondary eye care; Patient Safety and Quality of Care Improvements. This journal is indexed on PubMed
Dovepress

Central and CAS, and is the official journal of The Society of Clinical Ophthalmology (SCO). The manuscript management system is completely online and includes a very quick and fair peer-review system, which is all easy to use. Visit http://www.dovepress.com/ testimonials.php to read real quotes from published authors. 